\title{
RANKINGS: ESTRATÉGIA DE DEFESA DA UNIVERSIDADE PÚBLICA?
}

\author{
Lara Carlette Thiengo (UFVJM)* \\ https://orcid.org/0000-0003-3593-4746 \\ Lucídio Bianchetti (UFSC)** \\ https://orcid.org/0000-0001-9748-5646 \\ Maria de Lourdes Almeida Pinto (UNOESC-SC)*** \\ https://orcid.org/0000-0001-8515-2908
}

\section{RESUMO}

Neste artigo analisamos os limites da utilização de rankings para construir argumentações em defesa da universidade pública brasileira frente às tentativas de desqualificá-la. Objetivamos responder as seguintes questões: quais são os principais rankings veiculados e quais indicadores compõem as suas respectivas métricas? Quais são os limites dessas tabelas classificatórias apontados pela literatura acadêmica e pelos meios de comunicação? De que maneira, nos discursos midiáticos, são utilizados os resultados dos rankings para defender / atacar a universidade pública? Que argumentações são utilizadas? Neste contexto resulta preocupante o fato de o atual governo sequer considerar, em suas decisões e proposições, os informes, embora parciais e imprecisos, sobre a posição das universidades brasileiras nos rankings. Em termos metodológicos, utilizamos a análise da métrica de dois reconhecidos rankings internacionais e matérias jornalísticas, relacionadas ao tema, publicadas no ano de 2019.

Palavras-chave: Rankings. Mídia. Avaliação da educação superior.

\section{ABSTRACT}

\section{RANKINGS: DEFENSE STRATEGY OF THE PUBLIC UNIVERSITY?}

In this article the limits of the use of rankings to construct the arguments in defense of the Brazilian public initiative against the attempts of disqualification were analyzed. We aim to answer the following questions: What are the main rankings served and which indicators make up their respective metrics? Are the classification tables pointed out in the academic literature and in the media? In what way, in media discourses, are the results of the rankings to defend/ attack the public university? What arguments are used? In this context, it is worrying that the current government does not even consider, in its decisions

Pós Doutoranda em Educação pela Universidade do Oeste de Santa Catarina (UNOESC). Doutora em Educação pela Universidade Federal de Santa Catarina (UFSC). Professora Adjunta da Universidade Federal dos Vales de Jequitinhonha e Mucuri (UFVJM). E-mail: laracarlette@gmail.com

** Doutor em Educação pela Pontifícia Universidade Católica de São Paulo (PUC-SP). Professor Aposentado/Voluntário do Programa de Pós-Graduação em Educação da Universidade Federal de Santa Catarina (UFSC). E-mail: lucidiob@gmail.com

*** Doutora em Educação pela Universidade Estadual de Campinas (Unicamp). Docente Pesquisadora do Programa de PósGraduação em Educação da Universidade do Oeste de Santa Catarina (UNOESC- SC) na linha de pesquisa Educação, Políticas Públicas e Cidadania. E-mail: malu04@gmail.com 
and propositions, the reports, although partial and imprecise, about the position of Brazilian universities in the ranking. In methodological terms, it uses an analysis of the second generation of international rankings and of journalistic matters, related to the theme, published in the year 2019.

Keywords: Rankings. Media. Evaluation of higher education.

\section{RESUMEN}

\section{RANKINGS: ¿ESTRATEGIA DE DEFENSA DE LA UNIVERSIDAD PÚBLICA?}

En este artículo analizamos los límites de la utilización de rankings para construir argumentaciones en defensa de la universidad pública brasileña ante a los intentos de descalificarla. Objetivamos contestar a las siguientes cuestiones: ¿cuáles son los principales rankings vehiculados y qué indicadores componen sus respectivas métricas? ¿Cuáles son los límites de esas tablas clasificadoras señaladas por la literatura académica y por los medios de comunicación? ¿De qué manera, en los discursos mediáticos, se utilizan los resultados de los rankings para defender/atacar la universidad pública? ¿Qué argumentaciones son utilizadas? En este contexto resulta preocupante el hecho de que el actual gobierno siquiera considera, en sus decisiones y proposiciones, los informes, si bien parciales e imprecisos, sobre la posición de las universidades brasileñas en los rankings. En términos metodológicos, utilizamos el análisis de la métrica de dos reconocidos rankings internacionales y materias periodísticas, relacionadas con el tema, publicadas en el ano de 2019.

Palabras-clave: Rankings. Media. Evaluación de la educación superior.

\section{Introdução}

A recente polêmica envolvendo os pronunciamentos do atual governo brasileiro sobre a ineficiência e a irrelevância das universidades públicas tem levado várias entidades, associações, sindicatos, Instituições de Ensino Superior (IES), professores, institutos de pesquisa e até a imprensa a manifestarem-se contra tais ataques. Nessas manifestações tem-se afirmado e demonstrado justamente o oposto: a qualidade das universidades públicas e a sua relevância na produção e veiculação de conhecimentos e no desenvolvimento de pesquisas de ponta, básica e aplicada.

Nesse cenário, os rankings acadêmicos nacionais e internacionais passam a ser considerados, na maioria das vezes, como as principais e mais fidedignas fontes de dados para corroborar a qualidade e a relevância dessas instituições. Todavia, nesse processo, são relegadas a segundo plano questões como: o que efetivamente medem esses rankings? 0 que as universidades fazem com os rankings $\mathrm{e}$ o que os rankings fazem com elas? Que papéis desempenham esses mecanismos métricos no âmbito da elaboração de políticas públicas para a educação superior e para a própria gestão institucional? Em que medida os rankings efetivamente conseguem medir a qualidade da universidade pública brasileira, considerando as especificidades do nosso contexto? Por meio dos rankings é possível apreender e expressar o ser/fazer da universidade em sua totalidade?

Se olharmos retrospectivamente para o discurso da imprensa nos últimos anos, percebemos que os rankings também vieram servindo como "evidência" numérica e comparativa entre universidades intra e entre países e blocos, de modo a endossar o discurso de desmonte 
da universidade pública, que vem acontecendo via corte orçamentário, aprofundamento da diferenciação institucional, criação de iniciativas de excelência e priorização de áreas consideradas estratégicas (THIENGO, 2018). Tal ofensiva à universidade pública vem sendo orquestrada pelo Banco Mundial em associação com as elites brasileiras, e expressa uma forma de ajuste às necessidades prementes da nova ordem neoliberal. 0 documento "Um ajuste justo: análise da eficiência e equidade do gasto público no Brasil" (BANCO MUNDIAL, 2017) foi elaborado visando apoiar as reformas regressivas articuladas no âmbito do Estado brasileiro. Neste sentido, no caso da educação, o documento era composto por recomendações que visavam a extinção das universidades públicas, o fim da gratuidade de ensino e a ampliação dos financiamentos aos estudantes mais pobres em instituições particulares.

Considerando o acima exposto, no presente artigo, temos como objetivo analisar os limites da utilização de rankings para argumentações em defesa/ataque da universidade pública. Para isso, organizamos o artigo em itens que intentam responder as seguintes questões: quais são os principais rankings e quais indicadores compõem as suas métricas? Quais os principais limites dessas tabelas classificatórias apontados pela literatura acadêmica? De que maneira o discurso midiático utiliza o resultado dos rankings para defender/atacar a universidade pública e quais os limites dessa argumentação?

Em termos metodológicos, utilizamos a análise das métricas e indicadores de dois principais rankings internacionais e um nacional, além de matérias jornalísticas que abordam o tema do artigo, em parte do ano de 2019 (janeiro a maio), no arquivo do Jornal Folha de S. Paulo ${ }^{1}$ e na plataforma Google Notícias. Os descritores utilizados foram: "rankings and universidade"; "rankings acadêmicos"; "ranking". Para além disso, lançamos mão do levantamento bibliográfico e de dados e análise

1 Considerado ser este o jornal de maior expressividade no Brasil, neste momento, seja pelo número de assinantes, seja pela sua linha editorial. documental, orientando-nos pela compreensão das contradições, das mediações e da totalidade histórica, considerando com isto: "apreender as determinações que constituem o núcleo fundamental de um fenômeno, sem o que esse fenômeno não se constituiria." (FRIGOTTO, 1991, p. 187).

\section{Rankings acadêmicos: qual qualidade está sendo medida?}

Não obstante a popularidade que os rankings acadêmicos vêm adquirindo (CALDERÓN, 2010; ORDORIKA; GÓMEZ, 2010), estes também têm sido objeto de críticas por parte de vários atores e autores ao longo das últimas duas décadas (ENDERS, 2015; MOURA; MOURA, 2013; THIENGO, 2018). Todavia, concordamos com Altbach e colaboradores (2010) quando afirmam que essas críticas não têm impedido a conquista de legitimidade e credibilidade desses indicadores, convertidos, em pouco tempo, em referentes de uma determinada excelência e qualidade.

Desse modo, os rankings internacionais podem ser considerados elementos-chave na governança transnacional, criando um contexto de discussão sobre os critérios apropriados para as comparações, o êxito e a legitimidade das instituições que apontam elementos para criar estândares organizacionais.

Assim, esses mecanismos de avaliação/classificação podem ser considerados instrumentos de legitimidade, de distinção e de poder, bem como dinâmicas "organizadoras" de reformas educacionais que, por sua vez, estão atreladas às grandes metas sociais e econômicas de cada país e à promoção da competitividade no âmbito da globalização (AZEVEDO, 2016; DIAS SOBRINHO, 2005; SHIROMA, 2016).

Considerando as métricas dos rankings Academic Ranking of World Universities (ARWU), Times Higer Education (THE) e Ranking Universitário Folha (RUF), entendemos que estes privilegiam os indicadores relacionados à pesquisa. 
No caso do $A R W U$, mais de $90 \%$ da métrica está relacionada à performance da investigação, registrada por meio de indicadores como o número de prêmios Nobel entre os ex-estudantes da instituição e o número de artigos e de citações nos estudos bibliométricos. O RUF também atribui a este indicador $42 \%$ da sua métrica. 0 THE possui dois critérios relaciona- dos diretamente à pesquisa - Pesquisa: reputação, orçamento e volume; Citações: influências da pesquisa. Todavia, outros critérios e seus respectivos indicadores, como ensino, por exemplo, também estão relacionados à pesquisa, ainda que não de forma "literal", como percebemos nos Quadros 1, 2 e 3, que apresentam os critérios e indicadores desses três rankings.

Quadro 1 - Critérios e indicadores do ranking Times Higher Educacion (THE)

\begin{tabular}{|c|c|c|c|}
\hline CRITÉRIOS & INDICADOR & DESCRIÇÃO & PESO \\
\hline \multirow{5}{*}{$\begin{array}{l}\text { Ensino: ambiente } \\
\text { de aprendizado }\end{array}$} & Reputação acadêmica & $\begin{array}{l}\text { Resultados obtidos por meio da pesquisa } \\
\text { de opinião entre os acadêmicos, sobre o } \\
\text { prestígio e reputação das instituições de } \\
\text { ensino }\end{array}$ & $15 \%$ \\
\hline & Doutores titulados & $\begin{array}{l}\text { Número de doutores titulados em rela- } \\
\text { ção ao tamanho do corpo docente da ins- } \\
\text { tituição }\end{array}$ & $6 \%$ \\
\hline & Alunos/Staff acadêmico & $\begin{array}{l}\text { Proporção entre número de alunos de } \\
\text { graduação admitidos em relação ao nú- } \\
\text { mero de docentes }\end{array}$ & $4,5 \%$ \\
\hline & Orçamento & $\begin{array}{l}\text { Relação entre o orçamento da instituição } \\
\text { e o número de docentes }\end{array}$ & $2,25 \%$ \\
\hline & $\begin{array}{l}\text { Doutorados/ } \\
\text { Bacharelados }\end{array}$ & $\begin{array}{l}\text { Proporção entre o número de doutora- } \\
\text { dos e de bacharelados concedidos }\end{array}$ & $2,25 \%$ \\
\hline \multirow{3}{*}{$\begin{array}{l}\text { Pesquisa: } \\
\text { reputação, } \\
\text { orçamento e } \\
\text { volume }\end{array}$} & Reputação em pesquisa & $\begin{array}{l}\text { Resultados obtidos por meio da pesquisa } \\
\text { de opinião entre os acadêmicos, sobre o } \\
\text { prestígio e reputação das instituições em } \\
\text { pesquisa }\end{array}$ & $18 \%$ \\
\hline & $\begin{array}{l}\text { Investimento em } \\
\text { pesquisa }\end{array}$ & $\begin{array}{l}\text { Relação entre orçamento destinado à } \\
\text { pesquisa e o número de docentes }\end{array}$ & $6 \%$ \\
\hline & Publicações & $\begin{array}{l}\text { Relação entre a quantidade de documen- } \\
\text { tos publicados (indexados no Wos da } \\
\text { Thomson Reuters) e entre o número de } \\
\text { docentes }\end{array}$ & $6 \%$ \\
\hline $\begin{array}{l}\text { Citações: influência } \\
\text { da pesquisa }\end{array}$ & Citações & $\begin{array}{l}\text { Número de citações recebidas na Wos } \\
\text { nos últimos } 5 \text { anos }\end{array}$ & $30 \%$ \\
\hline \multirow{3}{*}{$\begin{array}{l}\text { Perspectiva } \\
\text { internacional }\end{array}$} & $\begin{array}{l}\text { Estudantes estrangeiros e } \\
\text { nacionais }\end{array}$ & $\begin{array}{l}\text { Proporção de estudantes estrangeiros } \\
\text { em relação ao número de estudantes na- } \\
\text { cionais da instituição }\end{array}$ & $2,5 \%$ \\
\hline & $\begin{array}{l}\text { Docentes estrangeiros e } \\
\text { nacionais }\end{array}$ & $\begin{array}{l}\text { Proporção de docentes estrangeiros em } \\
\text { relação ao número de estudantes nacio- } \\
\text { nais da instituição }\end{array}$ & $2,5 \%$ \\
\hline & $\begin{array}{l}\text { Colaboração } \\
\text { internacional }\end{array}$ & $\begin{array}{l}\text { Número de artigos científicos produzidos } \\
\text { com um ou mais coautores estrangeiros }\end{array}$ & $2,5 \%$ \\
\hline $\begin{array}{l}\text { Captação de } \\
\text { Recursos da } \\
\text { Indústria: inovação }\end{array}$ & Recursos da indústria & $\begin{array}{l}\text { Mede o peso de recursos destinados à } \\
\text { pesquisa provenientes da indústria em } \\
\text { relação ao número de acadêmicos }\end{array}$ & $2,5 \%$ \\
\hline
\end{tabular}

Fonte: Elaborado pelos autores deste artigo com base em Santos (2015). 
Quadro 2 - Critérios e indicadores do Academic Ranking of World Universities (ARWU)

\begin{tabular}{|l|l|c|c|}
\hline \multicolumn{1}{|c|}{ CRITÉRIOS } & \multicolumn{1}{|c|}{ INDICADOR } & CÓDIGO & PESO \\
\hline $\begin{array}{l}\text { Qualidade da } \\
\text { educação }\end{array}$ & Ex-alunos com medalhas Fields e Prêmios Nobel & Alumi & $10 \%$ \\
\hline \multirow{2}{*}{$\begin{array}{l}\text { Qualidade do corpo } \\
\text { docente }\end{array}$} & Funcionários com medalhas Fields e Prêmios Nobel & Award & $20 \%$ \\
\cline { 2 - 4 } & $\begin{array}{l}\text { Pesquisadores mais cotados em 21 campus } \\
\text { disciplinares }\end{array}$ & HiCi & $20 \%$ \\
\hline \multirow{2}{*}{$\begin{array}{l}\text { Resultados das } \\
\text { pesquisas }\end{array}$} & Artigos publicados em Nature e Science & N\&S & $20 \%$ \\
\cline { 2 - 4 } & $\begin{array}{l}\text { Artigos citados em Science Citation Index-expanded e } \\
\text { Social Science Citation Index }\end{array}$ & SCI & $20 \%$ \\
\hline $\begin{array}{l}\text { Tamanho do } \\
\text { estabelecimento }\end{array}$ & $\begin{array}{l}\text { Resultados dos outros índices divididos pelo número } \\
\text { de funcionários do estabelecimento }\end{array}$ & Size & $10 \%$ \\
\hline
\end{tabular}

Fonte: Elaborado pelos autores deste artigo com base em Shangai Ranking (2018).

Quadro 3 - Critérios e indicadores do Ranking Universitário Folha (RUF)

\begin{tabular}{|l|l|c|}
\hline \multicolumn{1}{|c|}{ CRITÉRI0 } & \multicolumn{1}{|c|}{ INDICADORES } & PORCENTAGEM \\
\hline \multirow{5}{*}{ Pesquisa } & $\begin{array}{l}\text { Total de publicações - 7\% } \\
\text { Total de citações - 7\% } \\
\text { Citações por publicação - 4\% } \\
\text { Publicações por docente - nos últimos anos - 7\% } \\
\text { Publicações por docente - ano anterior - 7\% } \\
\text { Publicações em revistas nacionais - 3\% } \\
\text { Recursos recebidos por instituição - 3\% } \\
\text { Bolsistas CNPq - 2\% } \\
\text { Teses - 2\% }\end{array}$ & \\
\hline Ensino & $\begin{array}{l}\text { Avaliadores do MEC - 20\% } \\
\text { Professores com doutorado e mestrado - 4\% } \\
\text { Professores em dedicação integral e parcial - 4\% } \\
\text { Nota no Enade - 4\% }\end{array}$ & \\
\hline Mercado & $\begin{array}{l}\text { Considera a opinião de 5.444 profissionais de RH } \\
\text { consultados pela Datafolha em 2016, 2017 e 2018 } \\
\text { sobre preferências de contratação }\end{array}$ & \\
\hline Internacionalização & $\begin{array}{l}\text { Citações internacionais por docente - 2\% da nota total } \\
\text { Publicações em coautoria internacional - 2\% }\end{array}$ & $32 \%$ \\
\hline Inovação & $\begin{array}{l}\text { Patentes - 2\% } \\
\text { Parceria com empresas - 2\% }\end{array}$ & \\
\hline
\end{tabular}

Fonte: Elaborado pelos autores deste artigo com base em Ranking Universitário Folha (2018).

A utilização do indicador "pesquisa" evidencia a noção de universidade prioritariamente enquanto espaço de produção de pesquisas e ainda a própria noção de ciência articulada ao produtivismo acadêmico. Neste sentido, os principais critérios relacionados à pesquisa são citações, indexação, total de publicação e publicação em revistas específicas (para o caso 
de ARWU e THE). Os rankings dependem da Thomson Reuters e Scopus, que coletam dados de citações em aproximadamente nove mil artigos de revistas na Web of Science e 18 mil na Scopus, respectivamente (HAZELKORN, 2013).

Hazelkorn (2013) explicita alguns problemas relacionados a esse indicador, dentre os quais destaca: a) os artigos podem ser citados por causa de erros, e não necessariamente em razão de sua qualidade; b) a revisão pelos pares pode ser uma influência conservadora em relação aos novos campos de pesquisa ou ideias que desafiam a ortodoxia; c) o critério de citações para medir o "impacto" sugere que sua relevância e benefício são simplesmente fenômenos da academia, ignorando assim os benefícios que a investigação e a inovação podem gerar; d) a depender da disciplina, os resultados da pesquisa e análise podem ser publicados em uma variedade de formatos.

Em contrapartida, os indicadores referentes ao ensino incluem questões como: reputação sobre o ensino, a proporção professor-aluno, a proporção de doutores em relação aos demais membros da equipe e outras semelhantes. A relação quantitativa tem como fundamento a ideia de que salas de aulas com menos alunos permitem uma melhor qualidade da educação. Entretanto esta relação não avalia a qualidade dos profissionais, tampouco o ambiente de aprendizagem, que também tem impacto sobre o desempenho dos alunos.

A quantidade de recursos também é utilizada como um indicador do ambiente de aprendizagem, representado pelo montante total do orçamento da IES ou pelo tamanho da coleção da biblioteca. Mais uma vez, a relação recursos por aluno pode ocultar dados da realidade, uma vez que existem faculdades ofertando grande variedade de programas e serviços ou dispendendo grandes gastos com dormitórios, instalações desportivas e de lazer, os quais serão todos interpretados como gastos por aluno. Há, neste aspecto, uma linha tênue entre o real impacto desses gastos nas experiências de aprendizagem dos alunos, que se modifica de acordo com o que se entender por "assistência estudantil", o que realmente pode ter impactos na aprendizagem, uma vez que diz respeito à oferta de recursos para que o estudante se mantenha na universidade ou ainda que figure com um "luxo para atrair alunos".

Essa abordagem também pode penalizar as instituições que tentam reduzir suas despesas ou que efetivamente contam com menos recursos.

0 indicador" perspectiva internacional" contabiliza o número de estudantes e professores de outros países na IES e os artigos em colaboração com docentes de instituições de outros países.

Todavia é importante considerar que o indicador de internacionalização é paralelo a outros, como a qualidade do corpo docente, que possui bastante expressividade nos referidos rankings e está articulado ao processo de internacionalização, na medida em que há um "mercado de cérebros" que move professores e alunos de prestígio entre universidades em todo o mundo. 0 investimento em pesquisa em redes de colaboração e as publicações em revistas internacionais também podem ser considerados fatores relacionados à internacionalização.

Outra questão proeminente é o fato de o maior número de revistas incluídas nas bases de dados serem publicadas em inglês, tornando-se mais fácil para os falantes nativos e professores das universidades de língua inglesa terem acesso aos principais jornais e editores, juntarem-se às redes informais que tendem a dominar a maioria das disciplinas científicas, além de, efetivamente, publicar neste idioma.

Outra questão relaciona-se ao tamanho e ao orçamento das IES ranqueadas. Neste sentido é atribuída maior importância às instituições de ensino superior com 25 mil estudantes ou mais, 2,5 mil professores e um orçamento anual de cerca de 2 bilhões de euros (USHER, 2015). De acordo com Hazelkorn (2013), apesar de existirem mais de 16 mil instituições 
de educação superior em todo o mundo, os rankings geralmente publicam dados relativos a apenas uma fração delas. Ainda de acordo com essa autora, as declarações de políticos e líderes universitários, bem como os meios de comunicação, se concentram nas conquistas das 100 primeiras universidades ranqueadas, o que representa menos de $1 \%$ das instituições de ensino superior existentes.

Partindo do entendimento de que os indicadores e os percentuais a eles atribuídos refletem juízos de valor e prioridades das organizações ranqueadoras, consideramos que as metodologias adotadas pelos rankings analisados têm um perfil elitista e não objetivam abranger grande número de instituições.
Embora a proposta da investigação em relação aos rankings não esteja fundamentada na análise do lugar ocupado pelo Brasil nessas tabelas de classificação, haja vista as críticas relacionadas a eles tecidas até aqui, optamos por apresentar e ponderar alguns dados sobre a questão. A intenção, neste sentido, é situar o Brasil na discussão estabelecida, bem como indicar alguns de seus desdobramentos no cenário brasileiro.

No Quadro 4 apresentamos as primeiras universidades brasileiras que aparecem nos rankings AWRU e THE, bem como suas respectivas posições, de acordo com dados divulgados por estes institutos em 2017, referentes ao ano de 2016.

Quadro 4 - Colocação das universidades brasileiras nos rankings AWRU e THE

\begin{tabular}{|c|c|c|}
\hline RANKINGS & POSIÇÃO & UNIVERSIDADE \\
\hline \multirow{6}{*}{$A W R U$} & 77 & Universidade de São Paulo - USP \\
\hline & 298 & Universidade Federal do Rio de Janeiro - UFRJ \\
\hline & 360 & Universidade Estadual de Campinas - Unicamp \\
\hline & 372 & Universidade Estadual de São Paulo - Unesp \\
\hline & 398 & Universidade Federal do Rio Grande do Sul - UFRGS \\
\hline & 406 & Universidade Federal de Minas Gerais - UFMG \\
\hline \multirow{6}{*}{$\begin{array}{c}\text { Times Higher } \\
\text { Education (THE) }\end{array}$} & $251-300$ & Universidade de São Paulo - USP \\
\hline & $401-500$ & Universidade Estadual de Campinas - Unicamp \\
\hline & \multirow{4}{*}{$601-800$} & Universidade Federal do Rio Grande do Sul - UFRGS \\
\hline & & Universidade Federal de Minas Gerais - UFMG \\
\hline & & Pontifícia Universidade Católica do Rio de Janeiro - PUC/RJ \\
\hline & & Universidade Federal do Rio de Janeiro - UFRJ \\
\hline
\end{tabular}

Fonte: Elaborado pelos autores deste artigo.

Com base no Quadro 4, percebemos que a Universidade de São Paulo (USP) aparece sempre em primeiro lugar entre as universidades brasileiras, apesar de ocupar distintas classificações no conjunto global de instituições. Essa diferenciação de posição da instituição em cada ranking está relacionada aos indicadores e às metodologias utilizados por cada um deles, como especificamos anteriormente.
Ao observar as demais IES brasileiras que ocupam as quatro posições seguintes, percebemos que se trata de um grupo determinado de instituições, formado basicamente pelas mesmas universidades em posições alternadas. 0 núcleo comum é formado por Unicamp, UFRJ, UFMG e UFRGS - aleatoriamente, foram ranqueadas PUC-Rio e Unesp -, todas elas instituições de caráter público, com exceção 
da PUC-Rio, caracterizada como confessional, sem fins lucrativos.

A despeito das diferenças metodológicas, as universidades com melhor posição no Ranking
Universitário Folha (RUF) correspondem ao mesmo grupo de IES que ocupam as primeiras posições nos rankings internacionais, como explicitado no Quadro 5.

Quadro 5 - Classificação Ranking Universitário Folha (RUF)

\begin{tabular}{|c|l|}
\hline Posição & Universidade \\
\hline 1 & Universidade de São Paulo (USP) \\
\hline 2 & Universidade Federal do Rio de Janeiro (UFRJ) \\
\hline 3 & Universidade Federal de Minas Gerais (UFMG) \\
\hline 4 & Universidade Estadual de Campinas (Unicamp) \\
\hline 5 & Universidade Federal do Rio Grande do Sul (UFRGS) \\
\hline
\end{tabular}

Fonte: Ranking Universitário Folha (2018).

Ou seja, assim como há uma repetição de universidades nos primeiros lugares dos rankings internacionais, percebe-se um processo similar em curso no Brasil, o qual, da mesma forma, insere-se em uma lógica que perpetua/ reforça determinadas características na elaboração dos ranqueamentos e, ao mesmo tempo, induz a organização e os objetivos das IES.

O mesmo ocorre em relação aos Programas de Pós-graduação com melhores avaliações por parte da Capes, uma vez que as métricas utilizadas nas tabelas classificatórias, de modo geral, privilegiam a pesquisa, que, por sua vez, ocorre de forma mais contundente no âmbito da pósgraduação. Do mesmo modo, a produção de artigos com alto fator de impacto, a concessão de prêmios e a articulação internacional também estão relacionadas a este estágio acadêmico.

Santos (2015), ao analisar a influência da produção científica brasileira e suas áreas de destaque nos principais rankings internacionais, revela que a contribuição do país para a produção científica mundial registrou crescimento de $100,34 \%$ considerando o período 2003-2012, ultrapassando o crescimento mundial, que foi de 40,50\%. As áreas de destaque da produção brasileira foram: Medicina Clínica, Física, Geociências e Ciências Espaciais. Assim, concordamos com a autora no entendimento de que os próprios resultados dos rankings são utilizados para localizar os nichos de excelência de cada instituição ou país, o que pode auxiliar no processo de tomada de decisões em relação à canalização de esforços e recursos em algumas universidades e áreas.

Em sua tese, Berg (2015) buscou desvelar a predominância dos três maiores rankings globais e sua relevância para as universidades de países considerados emergentes, neste caso, a USP. 0 autor conclui que esses rankings são medidas inadequadas de desempenho para instituições modernas de pesquisa e não fornecem metas realistas nem desejáveis para universidades fora do sistema anglo-americano.

\section{Rankings na mídia nacional}

De saída, é importante destacar o motivo pelo qual o discurso midiático interessa e deve ser considerado como importante referencial de análise. Partimos da compreensão que as classes dominantes produzem o consenso organizando as esferas sociais de acordo com as tendências materiais e ideológicas transformadas em senso comum, ${ }^{2}$ que se confunde

2 Sobre o conceito de senso comum desenvolvido por Gramsci (2011), entendemos que se refere a uma visão de mundo expressa de forma fragmentada, desagregada e incoerente pelos agentes sociais, os quais reproduzem, sem questionamento, o que é afirmado pelas classes dominantes como verdade - uma verdade construída a partir de um ponto de vista particular e tornada universal no processo de convencimento ideológico. 
com a própria cultura hegemônica, na qual os valores são incorporados como naturais. Neste sentido, Gramsci (2011) considerava a imprensa como um destacado instrumento da sociedade civil, na disputa de ideias, na direção moral e intelectual e na orientação para as disputas concretas existentes na sociedade. Isto porque, de acordo com Neves e colaboradores (2010), para ser econômica, a dominação de classes precisa também ser cultural, ou seja, necessita forjar corações e mentes a partir da edificação de consensos.

Os meios de comunicação são, pois, organismos privados de hegemonia ${ }^{3}$ que contribuem, neste caso, com a produção de um consenso sobre qualidade na educação superior a partir da difusão dos rankings acadêmicos como medidores da excelência (GRAMSCI, 2011).

Frente ao exposto, apresentamos, em seguida, trechos de matérias que expressam o levantamento de material jornalístico considerando os descritores/buscadores: "rankings and universidades", "rankings acadêmicos", "rankings", "ranking universitário". Essa busca foi feita nas bases de busca de alguns meios de comunicação, mais particularmente no jornal Folha de S. Paulo e no Google Notícias, considerando os resultados para o ano de 2019.

No jornal Correio da Bahia, publicada no dia 30 de abril de 2019, em sua versão online, temos a manchete: "Acusada de 'balbúrdia', UFBA teve melhora de avaliação em ranking" (ACUSADA..., 2019). Tal discurso busca destacar

3 Gramsci entende que existem três organizações culturais "propriamente ditas": a igreja, a escola e a imprensa. A Imprensa tem aqui um sentido amplo, envolvendo editoras e meios audiovisuais e até mesmo a arquitetura e os nomes de ruas. Portanto, abrangendo amplamente a questão da ideologia, incluindo livros e revistas científicas, políticas e literárias tanto para a elite como para a vulgarização popular. Já os meios audiovisuais, como rádio, teatro e cinema, têm uma característica especial, pois permitem uma difusão ideológica com maior rapidez, maior raio de ação e efeito emotivo do que a imprensa escrita, porém, com menor poder de aprofundamento das questões. Gramsci (2011), ao considerar o papel de destaque dos meios de comunicação na arena de disputa hegemônica, ou seja, a sociedade civil enquanto aparelho privado de hegemonia, criticava o alinhamento ideológico dos jornais ao poder, bem como o controle do noticiário e da opinião, ainda que camuflados em recortes simplistas e conformistas. uma "contradição" no que se refere ao que vem sendo chamado de "balbúrdia" com a melhoria da IES na pontuação dos instrumentos dos rankings. Também no dia 30 de abril de 2019, a revista Fórum (online) publicou matéria com a seguinte manchete: "Universidades ameaçadas de corte por ministro aparecem em ranking do CRWU entre as 'melhores do planeta'". De acordo com a referida reportagem:

As três universidades citadas pelo ministro da Educação de Jair Bolsonaro, Abraham Weintrab, nesta terça-feira (30),que serão alvo de cortes por terem permitido que ocorressem atos políticos - classificados por ele como 'balbúrdia' - em seus campi, aparecem no ranking do World University Rankings (CWRU) entre as mil melhores do mundo.

As universidades citadas são: Universidade de Brasília (UnB), Universidade Federal Fluminense (UFF) e Universidade Federal da Bahia (UFBA).

De acordo com ele [ministro da educação], 'Universidades que, em vez de procurar melhorar o desempenho acadêmico, estiverem fazendo balbúrdia, terão verbas reduzidas', disse Weintrab em reportagem de Renata Agostini, na edição desta terça-feira (30) do jornal O Estado de S.Paulo. (UNIVERSIDADES..., 2019).

No Jornal Folha de S. Paulo, várias matérias sobre a questão foram publicadas, também articulando os cortes das universidades aos resultados delas nos rankings. Um exemplo é a reportagem sobre os protestos dos estudantes com o seguinte título: "Estudantes protestam em Salvador contra cortes nas universidades federais" (VALADARES, 2019). Entre seus conteúdos, a matéria cita o ranking produzido pela própria Folha, o Ranking Universitário Folha (RUF), destacando que:

Inicialmente, o corte de recursos foi anunciado para três universidades federais: UnB (Universidade de Brasília), UFBA e UFF (Universidade Federal Fluminense). As instituições de ensino ficaram entre as 20 melhores universidades do país na última edição do RUF (Ranking Universitário Folha). Segundo a plataforma de produção acadêmica Web of Science, as três estão entre as 11 instituições brasileiras que mais ampliaram 
o número de artigos de 2008 a 2017. (VALADARES, 2019).

A matéria publicada dias antes pelo mesmo veículo com o título: "MEC estende corte de $30 \%$ de verbas a todas universidades federais" (SALDAÑA, 2019) utiliza exatamente as mesmas informações.

Na seção "análise", na matéria "Alvos de corte, universidades federais deram salto de produção em 10 anos. Ação do Ministério da Educação vai de encontro a indicadores de desempenho" (RIGHETTI; GAMBA, 2019), a situação dos cortes orçamentários às universidades acusadas de "balbúrdia" é comparada com o cenário internacional, afirmando que “Em países sérios, dados do ensino superior relacionados ao desempenho acadêmico das universidades, impacto social, sucesso dos egressos e outros indicadores são usados para orientar políticas públicas" (RIGHETTI; GAMBA, 2019). No trecho que segue, a afirmação do ministro de que as universidades estariam fazendo "balbúrdia" no lugar de melhorar seu desempenho acadêmico é explicitamente confrontada com base nos resultados do RUF, nos números de crescimento da produção científica da base de dados Scopus (que também é fonte de dados do ranking), número de doutores, tradição e organização das IES em análise:

A afirmação está equivocada. As federais de Brasília, da Bahia e Fluminense estão entre as 20 melhores universidades brasileiras no RUF - Ranking Universitário Folha desde a sua primeira edição (de 2012). No RUF 2018, a UnB figura em 9o lugar nacionalmente, a UFBA em $14^{\circ}$ e a UFF em 16으. [...]. Todas as 196 universidades públicas e privadas brasileiras foram classificadas na listagem. [...] UnB, UFBA e UFF são universidades com mais de 50 anos. São consideradas antigas para os padrões do nosso ensino superior brasileiro, que é bastante jovem, e com grande potencial de influenciar academicamente as escolas mais recentes. Também são universidades 'plenas' porque contam com programas de pós-graduação em todas as áreas do conhecimento (das 63 universidades federais ativas, somente 26 podem ser consideradas plenas). Estão, ainda, entre as 20 universidades do país que mais formam doutores em números absolutos. (RIGHETTI; GAMBA, 2019).

À primeira vista, poderíamos considerar essa argumentação elogiável, pois: como uma universidade que é relacionada com espaço de balbúrdia (no sentido de liberdade para protestar) pode ser produtiva e avançar na tabela de classificação das instituições? Todavia, este mesmo raciocínio pode reforçar a ideia de que apenas essas universidades - que avançam nos rankings - não podem ser consideradas espaço de balbúrdia porque são bem avaliadas na medição dos critérios indicados no item anterior.

Percebemos que não há uma defesa ampla e integral sobre a importância da universidade pública para o nosso país, e sim uma argumentação pautada na negação da adjetivação de espaço de balbúrdia, a partir dos melhores resultados nos rankings. Desse modo, cabe a indagação: e as outras universidades? E as universidades que não alcançam boa classificação nos rankings internacionais? Considerando nossa breve exposição sobre os principais indicadores desses rankings, podemos dizer que as universidades não bem avaliadas por estes instrumentos possuem menos qualidade ou excelência?

Após o pronunciamento no corte das verbas de algumas universidades associadas à "balburdia”, o Ministério da Educação retratou-se em nova nota oficial. Contudo, ao invés de recuar, "dobra a aposta", estendendo o corte linear de $30 \%$ a todas as universidades públicas. Conforme nota divulgada:

O Ministério da Educação informa que o critério utilizado para o bloqueio de dotação orçamentária foi operacional, técnico e isonômico para todas as universidades e institutos, em decorrência da restrição orçamentária imposta a toda Administração Pública Federal por meio do Decreto $\mathrm{n}^{\circ}$ 9.741, de 28 de março de 2019.0 bloqueio foi de $30 \%$ para todas as instituições. Nesse sentido, cabe esclarecer que do orçamento anual de despesas da Educação, 149 bilhões de reais, 24,64 bilhão de despesas não obrigatórias, dos quais 5,8 bilhões foram contingenciados por este Decreto. 0 bloqueio decorre da necessidade 
de o Governo Federal se adequar ao disposto na LRF, meta de resultado primário e teto de gastos. 0 bloqueio preventivo incide sobre os recursos do segundo semestre para que nenhuma obra ou ação seja conduzida sem que haja previsão real de disponibilidade financeira para que sejam concluídas. Além disso, o bloqueio pode ser revisto pelos Ministérios da Economia e Casa Civil, caso a reforma da previdência seja aprovada e as previsões de melhora da economia no segundo semestre se confirmem, pois podem afetar as receitas e despesas da União.

Cabe, ainda, destacar que, até o momento, todas as universidades e institutos já tiveram $40 \%$ do seu orçamento liberado para empenho. Por fim, o MEC estuda aplicar outros critérios como o desempenho acadêmico das universidades e o impacto dos cursos oferecidos no mercado de trabalho. 0 maior objetivo é gerar profissionais capacitados e preparados para a realidade do país. (BRASIL, 2019, grifo nosso).

Para fins de nossa análise, importa salientar que a nota explicita a intenção do governo em aplicar critérios de desempenho para conduzir uma política de financiamento.

Após essa nota, várias universidades passaram a se pronunciar questionando os cortes, visto a previsão de incapacidade financeira para continuarem funcionando sem prejuízo nas atividades de ensino, pesquisa e extensão no próximo semestre deste ano. Outra vez, os rankings são os principais argumentos que reforçam que determinadas universidades não podem sofrer cortes. Neste sentido:

A UFJF tem reconhecimento regional e impacto nacional: para o ranking da Folha [de São Paulo], a UFJF é a terceira de MG e a 23a universidade brasileira (2017 e 2018) entre 196 instituições, ocupando a oitava posição nacional em internacionalização; no ranking da U.S. News World Report, é a $2^{\underline{a}}$ de MG e $14^{\text {a }}$ no Brasil, 29a na América Latina e figura entre as mil melhores universidades do mundo. Independente do debate sobre os rankings, que possuem grande variação e diferentes metodologias, a UFJF aparece com dados significativos, informa a nota. (UNIVERSIDADES..., 2019).

A própria Coordenação de Aperfeiçoamento de Pessoal de Nível Superior (Capes) divulgou relatório produzido pela empresa estadunidense Clarivate Analytics ${ }^{4}$ sobre a pesquisa científica no Brasil entre 2011 e 2016. Destacam-se no relatório três conclusões: praticamente só há produção de pesquisa científica em universidades públicas; há pouco impacto internacional na produção científica brasileira; apenas Petrobrás e indústrias farmacêuticas realizam investimento relevante nessa área no país (CROSS; THOMSON; SINCLAIR, 2017).

Além disso, o relatório demonstra que praticamente não há produção científica em instituições privadas no Brasil. Entre as 20 instituições que mais produziram papers e que mais tiveram impacto estão 15 universidades federais e cinco universidades estaduais. A Universidade de São Paulo (USP), estadual, lidera a produção quantitativa, enquanto a Universidade do Estado do Rio de Janeiro (UERJ), também estadual, é a que apresenta produção de maior impacto. 0 relatório mostra que as universidades públicas produzem artigos científicos altamente citados e que alcançaram boas taxas entre 1\% dos papers mais citados do mundo.

\section{Reforçando o mercado dos rankings ou defendendo a Universidade pública: mercado dos rankings e rankings para 0 mercado}

Certamente, este é um momento conturbado politicamente, mas também bastante oportuno para que as empresas e mídias produtoras e consultoras de rankings reforcem e divulguem a relevância de seus produtos. Há, como indicam Robertson e Olds (2012), um verdadeiro mercado de rankings e para os rankings acadêmicos.

De acordo com Ball (2014) e Barabasch e Petrick (2012), essas empresas são especializadas em oferecer suporte material, técnico e ainda recursos financeiros, assessorias

4 Vinculada à multinacional Thomson Reuters. 
para implantação, mensuração, plataforma tecnológica, dados e informações estatísticas, serviços de comparações, criação de rankings, entre outros serviços. Assim, dentre as funções primordiais dessas empresas está a "produção de fatos" e "verdades" a partir dos números. St. Clair (2006, p. 68) entende que:

0 papel crucial dessas instituições é, portanto, assegurar a estabilidade entre os domínios da ciência e da política, falar com os diretores em ambos os domínios e fazê-lo de uma forma tal que a integridade e a produtividade possam ser asseguradas. Falando de forma diferente para diferentes públicos, as organizações de fronteira podem trazer estabilidade para questões normalmente controversas. Podem ser uma maneira de evitar tornar política a ciência, bem como tornar científica a política.

Também foram criados novos empreendimentos especializados nos rankings, como os aplicativos para smartphones em que é possível comparar universidades e rankings, conferências, especializações e consultorias. Ou seja, essas iniciativas representam formas de transformar em mercadoria os dados do ensino superior.

É interessante notar que os principais rankings globais oferecem palestras e seminários em vários países do mundo, a fim de "orientar" a utilização desses meios para escolha das futuras universidades, criando formas de interação direta com o público-alvo, neste caso, os estudantes e suas famílias.

Essas instituições ranqueadoras também patrocinam grandes fóruns e eventos, que têm como objetivo discutir os rankings. Aliás, o número de eventos com esse escopo tem crescido consideravelmente nos últimos anos.

De outra maneira, os rankings passam a ser utilizamos pelas consultorias internacionais de rating. Empresas como estas trabalham com ratings ou notações de crédito, que são opiniões sobre risco de crédito com as quais se avalia a capacidade e disposição de um emissor, como uma corporação, uma universidade, um governo estadual ou municipal, para cumprir suas obrigações financeiras.
Robertson e Olds (2012) afirmam que as agências de notação de crédito desempenham um papel-chave cada vez mais importante na governança global do ensino superior ao produzirem as suas avaliações sobre a viabilidade do crédito das universidades e, portanto, da capacidade da universidade em contrair empréstimos a taxas respeitáveis. Sinclair (2005) chama atenção para o fato de a classificação de crédito ser um grande negócio, uma vez que as duas principais agências de notação de crédito, a Moody's e a Standard \& Poor's, movimentam em torno de 30 trilhões de dólares em títulos a cada ano.

Classificações também afetam as taxas ou os custos de empréstimo, de modo que quanto maior for a classificação, menor o risco de descumprimento no reembolso ao credor e, portanto, menor o custo para o mutuário. "As universidades com diferentes classificações de crédito serão, portanto, colocadas de forma diferente para emprestar - de modo que o adágio de 'quanto mais você tem, mais você ganha' se torna um tema importante." (ROBERTSON; OLDS, 2012, p. 5). Assim, universidades bem ranqueadas têm mais facilidades para atrair investidores e estudantes, e os ranqueamentos podem afetar a política sistêmica de educação superior de alguns países, com instituições de classe mundial sendo financiadas às custas de instituições que fazem avançar outros objetivos.

Além de avaliar especificamente a capacidade de crédito das instituições, os dados dos rankings também são utilizados como um dos vários elementos para medir a atratividade dos países em relação a investimentos. Nesta lógica, a eficiência do sistema de educação superior é de significativa relevância, porque representa um dos principais fatores responsáveis pela formação de força de trabalho adequada às demandas do mercado, assim como se configura enquanto lócus da produção científica, especialmente daquela atrelada à inovação. Evidentemente, o perfil do sistema de educação superior do país também está diretamente re- 
lacionado aos diferentes tipos de investimentos e investidores.

\section{Considerações Finais}

Apesar das novas feições e do tom mais agressivo que vem delineando o discurso e as ações que desqualificam a relevância da universidade pública brasileira no âmbito do projeto educacional ${ }^{5}$ do Governo Jair Messias Bolsonaro, não há grande novidade quando tratamos do discurso de desqualificação dos serviços públicos (incluindo as áreas sociais) em tempos de avanço do neoliberalismo, que teve início na década de 1990. Talvez se possa analisar a diferença no discurso (moralista) e nas estratégias do atual governo em relação àquelas do projeto neoliberal supranacional. Entretanto isto ainda seria prematuro. Por ora destacamos a continuidade em termos de políticas de cariz neoliberal, com destaque para a pavimentação do caminho visando a materialização de um Estado mínimo.

Compreendemos, pois, que a elaboração de argumentos em defesa da universidade pública não pode estar atrelada essencialmente aos resultados dos rankings acadêmicos, uma vez que estas tabelas classificatórias não dão conta de expressar a qualidade e o ser/fazer das IES em sua totalidade, além de serem ferramentas que dão guarida à meritocracia, à manutenção e ao aprofundamento do corte de classe no acesso ao ensino superior e que, desse modo, não correspondem à ideia de educação como bem público e social.

Por considerar que vai ao core da questão das métricas classificatórias, lançamos mão de uma longa citação, não para concluir, mas para alargar a compreensão e para subsidiar os necessários posicionamentos sobre os rankings e o que representam.

Os rankings mais importantes, o Quacquarelli Symonds (QS), o Times Higher Education (THE), o Academic Ranking of World Universities (ARWU), Ranking de Shangai etc. trabalham com critérios

5 Se é que podemos chamar de projeto. em que as nossas universidades não cabem. Não entram! É como sapatinho de cristal da Cinderela: não adianta querer botar um pé muito grande ali dentro. Praticamente metade do peso da avaliação diz respeito ao número de prêmios Nobel e o Brasil não tem nenhum. [...] Quase metade da avaliação da relevância científica é aferida por duas revistas, Nature e Science. [...] E não dá para todo mundo publicar em duas revistas, não é possível. Então, quando nas Relações Internacionais, pensando a internacionalização, usamos, 'bom, temos que melhorar a posição no ranking' é preciso explicitar exatamente o que se pretende com isso. Sabemos que hoje existe um ramo de negócio especializado em prestar consultoria para as universidades subirem nos rankings. Isso não tem sentido acadêmico verdadeiro. (LEAL; LEHER; AZEVEDO, 2018, p.10).

Como afirma Mészàros (2005), seria no mínimo um "milagre" esperar da sociedade capitalista uma sanção ativa (ou mesmo mera tolerância), um mandato que estimule as instituições de educação formal a contemplar de forma plena a grande tarefa histórica do nosso tempo: romper com a lógica do capital em favor da vivência digna do conjunto da humanidade e da sobrevivência do planeta. Por fim, ao considerar que, historicamente, as universidades públicas cumpriram, ainda que com limites e contradições, a função de espaços críticos das sociedades e de busca pela verdade, o momento é, sem dúvida, ameaçador. Todavia, reafirmar e lutar por um projeto de universidade pública com base na lógica de ranqueamentos é tão incoerente e ameaçador quanto o cenário que estamos vivendo.

E pensar que o atual governo sequer leva em conta essas métricas classificatórias que estão longe de expressar o que a universidade é e faz em sua acepção como universitas.

\section{REFERÊNCIAS}

ACUSADA de "balbúrdia", UFBA teve melhora em ranking. Correio da Bahia, Salvador, 30 abr. 2019. Disponível em: https://www.correio24horas.com. $\mathrm{br} /$ noticia/nid/acusada-de-balburdia-ufba-tevemelhora-de-avaliacao-em-ranking/. Acesso em: 30 maio 2019. 
ALTBACH, P. et al. Trends in global higher education: tracking an academic evolution. Boston: Sense Publishers, 2010.

AZEVEDO, M. L. N. A integração dos sistemas de educação superior na Europa. De Roma à Bolonha ou da integração econômica à integração acadêmica. In: SILVA JÚNIOR, J. dos R.; OLIVEIRA, J. F.; MANCEBO, D. (org.). Reforma universitária: dimensões e perspectivas. Campinas, SP: Alínea, 2016. p. 171-186.

BALL, S. J. Educação Global S. A.: novas redes políticas e o imaginário neoliberal. Ponta Grossa: UEPG, 2014.

BANCO MUNDIAL. Um ajuste justo: análise da eficiência e equidade do gasto público no Brasil. 2017. Disponível em: http://documents.worldbank.org/curated/en/884871511196609355/ pdf/121480-REVISED-PORTUGUESE-Brazil-Public-Expenditure-Review-Overview-PortugueseFinal-revised.pdf. Acesso em: 15 maio 2019.

BARABASCH, A.; PETRICK, S. Multi-level policy transfer in Turkey and its impact on the development of the vocational education and training (VET) sector. Globalisation, Societies and Education, v. 10, n. 1, p. 119-143, 2012. Disponível em: https:// bit.ly/2XRyHLr. Acesso em: 20 set. 2017.

BERG, J. H. A. Competindo no cenário mundial: a Universidade de São Paulo e o ranking global de universidades. 2015. 168 f. Dissertação (Mestrado em Relações Internacionais) - Universidade de São Paulo, São Paulo, 2015.

BRASIL. MINISTÉRIO DA EDUCAÇÃO. Nota pública. Bloqueio total do MEC nas universidades foi de 3,4\%. Disponível em: http://portal.mec.gov.br/ component/content/index.php?option=com_content\&view $=$ article \&id=75781: bloqueio-totaldo-mec-nas=-universidades-foi-de3-4-\&catid33381\&Itemid=86. Acesso em: 10 maio 2019.

CALDERÓN, A. I. A responsabilidade social da educação superior: uma leitura à luz das mudanças discursivas da Unesco. ENCONTRO NACIONAL DE DIDÁTICA E PRÁTICA DE ENSINO, 15., 2010, Belo Horizonte. Anais [...]. Belo Horizonte: UFMG, 2010. vol. 1, p. 30-42.

CROSS, D; THOMSON, S; SINCLAIR, A. Research in Brazil: a report for CAPES by clarivate analytics. Clarivate Analytics, 2017. Disponível em: http:// www.capes.gov.br/images/stories/download/ diversos/17012018-CAPES-InCitesReport-Final. pdf. Acesso em: 18 jan. 2019.
DIAS SOBRINHO, J. Dilemas de educação superior no mundo globalizado: sociedade do conhecimento ou economia do conhecimento? São Paulo: Casa do Psicólogo, 2005.

ENDERS, J. Una "carrera armamentista" en la academia: los rankings internacionales y la competencia global para crear universidades de clase mundial. Revista de la Educación Superior, v. 44, n. 176, p. 83-109, 2015.

FRIGOTTO, G. 0 enfoque da dialética materialista histórica na pesquisa educacional. In: FAZENDA, I. (org.). Metodologia da pesquisa educacional. São Paulo: Cortez, 1991. p. 69-90.

GRAMSCI, A. Cadernos do cárcere: os intelectuais; o princípio educativo; jornalismo. 6. ed. Vol. 2. Rio de Janeiro: Civilização Brasileira, 2011.

HAZELKORN, E. World-class universities or world class systems? Rankings and higher education policy choices. In: HAZELKORN, E.; WELLS, P.; MAROPE, M. (Ed.). Rankings and accountability in higher education: uses and misuses. Paris: UNESCO, 2013. p. 1-23.

LEAL, F. G.; LEHER, R.; AZEVEDO, M. L. N. Perspectivas e desafios para a educação superior na ALiCe o Caribe: entrevista com Roberto Leher, reitor da Universidade Federal do Rio de Janeiro, com comentários de Mário Luiz de Azevedo, da Universidade Estadual de Maringá. Arquivos Analíticos de Políticas Educativas, v. 26, n. 166, dez. 2018. Disponível em: http://dx.doi.org/10.14507/ epaa.26.4286. Acesso em: 05 mar. 2019.

MÉSZÁROS, I. A educação para além do capital. São Paulo: Boitempo, 2005

MOURA, B. A.; MOURA, L. B. A. Ranqueamento de universidades: reflexões acerca da construção de reconhecimento institucional. Acta Scientiarum, Maringá, PR, v. 35, n. 2, p. 213-222, dez. 2013. Disponível em: http://periodicos.uem.br/ojs/index. php/ActaSciEduc/article/view/20400/pdf. Acesso em: 20 out. 2018.

ORDORIKA, I.; GÓMEZ, R. R. El ranking Times en el mercado del prestigio universitario. Perfiles Educativos, v. 32, n. 129, p. 8-22, 2010. Disponível em: https://bit.ly/2F0jYW5. Acesso em: 20 set. 2017.

RANKING UNIVERSITÁRIO FOLHA 2018 (RUF). Classificação. São Paulo, 2018. Disponível em: http://ruf.folha.uol.com.br/2018/. Acesso em: 10 maio 2019.

RIGHETTI, S.; GAMBA, E. Alvos de corte, univer- 
sidades federais deram salto de produção em 10 anos. Folha de São Paulo, São Paulo, 30 abr. 2019. Disponível em: https://www1.folha.uol.com.br/ educacao/2019/04/alvos-de-corte-universidadesfederais-deram-salto-de-producao-em-10-anos. shtml. Acesso em: 15 maio 2019.

ROBERTSON, S. L.; OLDS, K. World university rankings: on the new arts of governing (quality). Bristol: Centre for Globalisation, Education and Societies, 2012.

SALDAÑA, P. MEC estende corte de $30 \%$ de verbas a todas universidades federais. Folha de S. Paulo, São Paulo. 30 abr. 2019. Disponível em: https:// www1.folha.uol.com.br/educacao/2019/04/mec-estende-corte-de-30-de-verbas-a-todas-universidades-federais.shtml. Acesso em: 05 maio 2019.

SANTOS, S. M. O desempenho das universidades brasileiras nos rankings internacionais: áreas de destaque da produção científica brasileira. 2015. 344 f. Tese (Doutorado em Ciência da Informação) - Universidade de São Paulo, São Paulo, 2015.

SHANGAI RANKING. Métrica do Shangai Ranking. Shangai, 2018. Disponível em: http://www. shanghairanking.com/pt/. Acesso em: 10 mar. 2019.

SHIROMA, E. O. Redes de políticas públicas e governança da educação - pesquisando a convergência das políticas para docentes nas agendas para a próxima década. Relatório de Pesquisa APQ/ CNPq. Florianópolis: UFSC, 2016.

SINCLAIR, T. J. The new masters of capital: american bond rating agencies and the politics of creditworthiness. New York: Cornell University Press, 2005.

ST. CLAIR, A. L. Global poverty: the co-production of knowledge and politics. Global Social Policy, v. 6, n. 1, p. 57-77, 2006. Disponível em: https://bit. ly/2Hi34Wt. Acesso em: 20 nov. 2017.
THIENGO, L. C. Universidades de classe mundial e o consenso pela excelência: tendências globais e locais. 366 f. Tese (Doutorado em Educação) - Programa de Pós-Graduação em Educação, Universidade Federal de Santa Catarina (UFSC), Florianópolis, 2018.

UNIVERSIDADES ameaçadas de corte por ministro aparecem em ranking do CRWU entre as "melhores do planeta". Fórum, São Paulo, 30 abr. 2019. Disponível em: https://www.revistaforum.com.br/ universidades-ameacadas-de-corte-por-ministro -aparecem-em-ranking-do-crwu-entre-as-melhores-do-planeta/. Acesso em: 30 abr. 2019.

UNIVERSIDADES Federais da Zona da Mata e Vertentes analisam impacto do bloqueio de verba pelo MEC. G1, Rio de Janeiro, 30 maio 2019. Disponível em: https://g1.globo.com/mg/zona-da-mata/ noticia/2019/05/03/universidades-federais-dazona-da-mata-e-vertentes-analisam-impacto-do -bloqueio-de-verba-pelo-mec.ghtml. Acesso em: 02 jun. 2019.

USHER, A. As melhores instituições de ensino superior do ranking Times Higher Education e a misteriosa "ascensão da Ásia". Ensino Superior, Campinas, SP, 2015. Disponível em: https://www. revistaensinosuperior.gr.unicamp.br/international-higher-education/as-melhores-instituicoesde-ensino-superior-do-ranking-times-higher-education-e-a-misteriosa-ascensao-da-asia. Acesso em: 20 out. 2018.

VALADARES, J. Estudantes protestam em Salvador contra cortes nas universidades federais. Folha de S. Paulo, São Paulo, 06 maio 2019. Disponível em: https://www1.folha.uol.com.br/educacao/2019/05/estudantes-protestam-em-salvadorcontra-cortes-nas-universidades-federais.shtml. Acesso em: 10 maio 2019.

Recebido em: 25/05/2019 Aprovado em: 26/07/2019 